\title{
Participação e conselhos gestores municipais
}

\author{
Janaína Rigo Santin* \\ Bruna Pertile Pandolfo**
}

Resumo: O artigo analisa os instrumentos de participação popular a partir da Constituição Federal de 1988, que institui como regime político no Brasil a democracia semidireta. O foco principal são os conselhos gestores municipais. Tratam-se de órgãos colegiados que congregam representantes da sociedade civil e da sociedade política, atuantes institucionalmente ao lado do Executivo Municipal na formulação, execução e controle das políticas públicas. Entretanto, para sua plena eficácia na realidade brasileira será necessário interesse público na reordenação da relação entre Estado e sociedade civil. Certamente, esse movimento resultará em uma nova forma de fazer e entender a política no país, o que não será fácil, tão pouco rápido, e que exige uma verdadeira mudança cultural na forma como é exercida a política no país. Resta para o Estado a seguinte opção: parar de governar o povo para governar para e junto ao povo. O método de abordagem adotado no desenvolvimento da pesquisa foi o dialético.

Palavras-chave: democracia; participação; conselhos gestores.

Abstract: This paper study the participation instruments in the 1988 Federal Constitution, establishing a semi-direct democracy in Brazil, with focus in municipal management councils. These are collegiate institutions that bring together civil society and political society, acting institutionally next to the City in the formulation, execution and control of public policies. However, to be fully effective in the Brazilian

\footnotetext{
* Possui Pós Doutorado em Direito Administrativo pela Universidade de Lisboa, Portugal, com bolsa CAPES, pelo período de 8 meses (2011). Doutorado em Direito pela Universidade Federal do Paraná (2004). Mestrado em Direito pela Universidade Federal de Santa Catarina (2000). Advogada e Professora Titular I da Universidade de Passo Fundo, nas disciplinas de direito municipal, direito urbanístico e direito das obrigações. Professora da Universidade de Caxias do Sul, das disciplinas de direito administrativo e direito constitucional. Faz parte do corpo docente permanente do Mestrado em Direito e do Mestrado e Doutorado em História da Universidade de Passo Fundo. É professora da Graduação e Pós-Graduação lato sensu da Faculdade de Direito da Universidade de Passo Fundo. É professora convidada do Mestrado em Ciências Jurídicas-Econômicas e Desenvolvimento e do Mestrado em Governação e Gestão Pública da Universidade Agostinho Neto, em Luanda, AngolaÁfrica.

** Bacharel em Ciências Jurídicas e Sociais pela UPF. Bolsista PIVIC/UPF
} 


\section{Revista Brasileira de História \& Ciências Sociais - RBHCS}

Vol. $8 \mathrm{~N}^{\circ}$ 16, Julho - Dezembro de 2016

reality will require public interest in reordering of the relationship between state and civil society. Certainly, this movement will result in a new way of doing and understanding politics in the country, which will not be easy, nor fast, and it requires a cultural change in the way politics in Brazil. It remains to state the following option: stop rule the people to rule and with the people. The method adopted in the research was the dialectic.

Keywords: democracy; participation; management councils.

\section{INTRODUÇÃO}

O presente trabalho visa analisar instrumentos de democracia participativa em âmbito local adotados no ordenamento jurídico brasileiro, em especial os conselhos gestores municipais, com vistas a apontar seus aspectos positivos e discutir suas principais limitações.

Os conselhos consagram-se como o instituto de participação popular mais atuante na esfera Executiva brasileira, exercendo atividades importantes na definição as políticas públicas municipais. Suas decisões são consultivas e também deliberativas. Ou seja, em alguns Conselhos Gestores como Saúde, Educação e Meio Ambiente, leis federais garantem a vinculação do gestor público ao que for decidido pelo Conselho Municipal.

Trata-se de mecanismo participativo destinado a aperfeiçoar as políticas públicas do país, fazendo com que sejam realizadas de acordo com os interesses e as necessidades reais daquela comunidade. O que mais se destaca como relevante neste instituto participativo é sua total institucionalização dentro da organização da administração pública. Trata-se de instância obrigatória para orientar as ações do Executivo e das secretarias municipais, representando uma proposta concreta e ativa de descentralização do poder e seu compartilhamento entre Estado e sociedade civil.

O Brasil, ao adotar a democracia como regime político, vincula-se às regras democráticas e deve atentar para a construção de uma nação de cidadãos comprometidos com o bem de todos. Essa transformação deve acontecer não somente dentro do espaço local, mas também ser compromisso de todos os entes da federação, com a finalidade de fazer valer uma sociedade igualitária, ativa e participativa politicamente, bem como um aparato estatal a serviço de sua população e não de seus representantes e de uma minoria ligada ao poder. 


\section{A gestão participativa no ordenamento jurídico brasileiro}

Segundo Carvalho (2016, p. 5), a Constituição Federal de 1988, reconhecida como "Constituição Cidadã", incorporou o pleno direito ao exercício da cidadania e à participação como um de seus mais importantes fundamentos. Além disso, contempla o mecanismo da democracia semidireta, previsto no artigo 1, parágrafo único, onde não só permite como também estimula a democracia participativa junto à representativa. E, nesse sentido, a atuação do cidadão nos conselhos gestores municipais vem para romper com a visão tradicional da política em que o cidadão encerra sua participação política após o voto.

Assim sendo, destaca-se os seguintes artigos da Constituição Federal de 88 capazes de concretizar o princípio da participação: artigos $5^{\circ}$, incisos XIV e XXXIII (garante o acesso de todos à informação administrativa); artigo 14 (plebiscito, referendo e iniciativa popular); art. 31, § $3^{\circ}$ (direito de fiscalização pelos contribuintes das contas dos Municípios); artigo 74, $\S 2^{\circ}$ (direito de denunciar irregularidades perante as Cortes de Contas); artigo 194, inciso VII (necessidade de observância do caráter democrático da seguridade social) e ainda os artigos 197, 198, 204 a 206, 216, 225, 227 e 231, os quais exigem uma gestão democrática na saúde, na assistência social, na cultura e no meio ambiente.

Em 2000 foi editada a Lei de Responsabilidade Fiscal (Lei Complementar 101/2000), com vistas a trazer novas diretrizes para as finanças públicas de todos os poderes públicos, em todos os níveis federativos brasileiros, voltadas para a responsabilidade na gestão fiscal. E um de seus princípios fundamentais é a transparência na gestão fiscal, que deve estar presente tanto na elaboração quanto na fiscalização das peças orçamentárias. Assim, conforme seu artigo 1. Parágrafo 1, dispõe que mediante uma ação planejada e transparente será possível prevenir riscos e corrigir desvios capazes de afetar o equilíbrio das contas públicas, bem como otimizar a aplicação dos recursos com vistas a atender as necessidades da população, e não apenas de uma minoria que está próxima aos mecanismos decisórios do poder.

Mas o princípio da participação na gestão pública também está contemplado na legislação infraconstitucional brasileira, em especial no que tange ao nível municipal, com edição do Estatuto da Cidade, em 2001, no qual positivou-se todo um capítulo sobre Gestão Democrática Municipal. A partir da sua edição tornou-se obrigatório em âmbito municipal a participação do cidadão na formulação, execução 


\section{Revista Brasileira de História \& Ciências Sociais - RBHCS}

Vol. $8 \mathrm{~N}^{\circ}$ 16, Julho - Dezembro de 2016

e acompanhamento de planos, projetos e programas de desenvolvimento urbano. $\mathrm{Ou}$ seja, após 2001 inseriu-se mais uma etapa no processo legislativo das leis urbanísticas: a participação popular dos cidadãos e das entidades organizadas da sociedade civil em audiências públicas, debates e consultas, tida como condição obrigatória para aprovação de grande parte das políticas públicas em âmbito municipal. Para Grazia

o controle social e a participação da população organizada são condições básicas para a conquista de direitos, de novas políticas públicas que incorporem os excluídos e de novas referências para as cidades. Por meio do exercício do controle social do Poder Público as organizações participam da gestão das cidades, daí o nome de Gestão Democrática da Cidade.” (GRAZIA, 2002, p. 18)

A participação pode ser entendida num sentido semântico como "uma forma ativa de integração de um indivíduo a um grupo" (MOREIRA NETO, 1992, p.18). Ou seja, a acepção significa fazer parte, tomar parte ou ser parte (BORDENAVE, 1995, p.22), "de um ato ou processo, de uma atividade pública, de ações coletivas", e que no fim permita chegar a "um consenso traduzível em decisões no sistema político". (TEIXEIRA, 2002, p.27)

Já na definição juspolítica, a participação consiste na "ação dos indivíduos e dos grupos sociais secundários nos processos decisórios do Estado ou de seus delegados”. (MOREIRA NETO, 2001, p.12). Nas palavras de Gohn, visa "fortalecimento da sociedade civil, não para que esta participe da vida do Estado, mas para fortalecê-la e evitar as ingerências do Estado”. (GOHN, 2001, p. 15).

Com isso, a sociedade civil atua de modo a auxiliar nas decisões para a realização de interesses gerais, a fim de otimizar as decisões administrativas. Atuar possibilitando a participação dos cidadãos na definição das tutelas jurídicas e políticas "não só ajuda as pessoas a interpretarem o fenômeno do governo como uma forma de ação, e não um mero tipo de acontecimento, mas leva-as a criticar a partir do ponto de vista de agentes, e não de espectadores”. (LUCAS, 1985, p. 112)

E isto somente será possível quando ocorrer "a participação como um processo, que significa perceber a interação contínua entre os diversos atores que são 'partes', o Estado, outras instituições políticas e a própria sociedade". (TEIXEIRA, 2002, p.27-28)

Entende Pateman (1992, p.33-39) que a participação "é fundamental para o estabelecimento e manutenção do Estado democrático, Estado esse considerado não 


\title{
Revista Brasileira de História \& Ciências Sociais - RBHCS
}

Vol. $8 \mathrm{~N}^{\mathrm{o}}$ 16, Julho - Dezembro de 2016

apenas como um conjunto de instituições representativas, mas aquilo que denomina de sociedade participativa”. Trata-se, portanto, de conjugar práticas participativas com representativas no exercício do poder político.

Entretanto, “o início de processos participativos está na capacidade de organização da sociedade civil, porque somente assim [esta] adquire vez e voz" (DEMO, 1993, p. 32). Assim, também entende Teixeira, que a “participação cidadã [é o] processo complexo e contraditório entre sociedade civil, Estado e mercado, em que os papéis se redefinem pelo fortalecimento dessa sociedade civil mediante a atuação organizada dos indivíduos, grupos e associações” (TEIXEIRA, 2002, p.30). Além disso, deve-se ter em vista que:

\begin{abstract}
A ideia tradicional de participação política, a princípio adstrita à atividade legislativa e à escolha de representantes, evoluía para uma concepção mais ampla, abrangendo todas as atividades do Estado, desdobrando as hipóteses de provocação de controle do Judiciário e, principalmente, multiplicando-se em inovadoras modalidades de participação administrativa. (MOREIRA NETO, 1992, p.16)
\end{abstract}

E a participação da sociedade civil no exercício do poder concretiza-se de maneira especial nos conselhos municipais, que são mecanismos institucionais de participação nas atividades estatais. Por certo não se almeja o fim da representação nem o exercício pleno do poder pela cidadania, mas o que se quer é uma gestão compartilhada entre sociedade civil e sociedade política, capazes de interagir para otimizar a aplicação do dinheiro público e a concretização dos direitos fundamentais.

Neste contexto, fica clara a importância do princípio democrático e da participação popular para a Constituição Federal de 1988 e demais legislação infraconstitucional, sendo a gestão democrática municipal via conselhos municipais uma importante ferramenta de gestão para a concretização de uma democracia participativa e não somente representativa. Quanto maior a educação política para a construção de um cidadão ativo, consciente de seus direitos e deveres, conjugada com práticas democráticas institucionalizadas nos três entes federativos, certamente se aumentará o grau de republicanismo e de responsabilidade dos gestores com a aplicação do dinheiro público.

\section{Conselhos Gestores: limites e possibilidades}


A existência de conselhos gestores municipais como ferramenta de gestão pela Administração Pública acompanha a criação da democracia, visto que já eram utilizados por Portugal em relação as suas colônias. No restante do mundo, os conselhos ganharam força em períodos de crise política e institucionais, uma vez que conflitavam com os modelos tradicionais. No Brasil, as primeiras tentativas de criação dos conselhos iniciaram com os chamados conselhos populares nos anos 80, tanto como estratégia de governo de oposição dentro das políticas da democracia participativa, quanto por movimentos organizados da sociedade civil, que buscavam participação popular em suas lutas por décadas contra o regime militar. Vislumbravam nos conselhos populares uma forma de organizar essas lutas políticas, fragmentadas na época. (GOHN, 2001, 65-75).

Atualmente, os conselhos gestores municipais possuem um papel de ferramenta da própria gestão pública, servindo como instrumento mediador na relação do Estado com a sociedade civil. Estão previstos na Constituição Federal de 1988 (veja-se os artigos 10; 194, inciso VII; 204, inciso II; 205 e 206, inciso VI; 206, parágrafo 1; 216-A e 227, parágrafo 1) e também em outras leis federais, estaduais e municipais, na qualidade de instrumento de expressão, representação e participação popular.

Desta forma, a criação e o funcionamento dos Conselhos Gestores transformaram-se em pré-requisitos obrigatórios para várias funcionalidades do Poder Executivo como, por exemplo: repasses de valores entre os entes federados nos campos da saúde, educação e cultura; assuntos de interesse de toda a comunidade como meio ambiente, defesa do consumidor e patrimônio histórico cultural; assim como também, assuntos que atentem a camadas específicas da população como criança e adolescente, idosos, mulheres etc. (GOHN, 2001, p. 8385)

Consagra-se como importante instituto de participação popular na esfera do Poder Executivo, exercendo ora funções consultivas ora caráter deliberativo na formulação das políticas públicas de governo. Caracteriza-se por ser um órgão colegiado criado ou autorizado por lei, que possui participação tanto de representantes da Administração Pública quanto da sociedade civil, e objetiva a tomada de decisões na esfera de sua competência. Sendo assim, o instituto desloca o poder decisório da chefia do Poder Executivo para a periferia de sua estrutura, 
Revista Brasileira de História \& Ciências Sociais - RBHCS

Vol. $8 \mathrm{~N}^{\mathrm{o}}$ 16, Julho - Dezembro de 2016

descentralizando o ato decisório e o aproximando da sociedade. (PEREZ, 2009, p.140-42)

Santin e Finamore definem os conselhos gestores municipais como espaços públicos concebidos para possibilitar que os interesses coletivos da sociedade integrem a agenda pública. A sociedade civil passa a participar efetivamente da gestão das políticas públicas (formalização, implementação e avaliação), constituindo-se assim em real espaço de construção da cidadania. (SANTIN; FINAMORE, 2007, p. 8). Em conformidade, na opinião de Berclaz,

Os conselhos sociais são mediações que, ao integrarem organicamente Estado e sociedade civil, destinam-se a garantir, por meio do exercício do poder cidadão e da efetividade do controle social, que as políticas públicas nos respectivos campos materiais de atuação sejam realizadas de modo coerente com as necessidades históricas de cada comunidade política, tudo de maneira a ampliar o horizonte de manutenção, reprodução e incremento da qualidade de vida do povo, razão de ser da política como atividade. (BERCLAZ, 2013, p. 330)

Assim, para o autor os conselhos são, resumidamente: "[...] colegiados compostos de modo paritário entre governo e não governo que exercem papel de controle e deliberação de políticas públicas e atuam de modo democrático e autônomo na tríplice esfera federativa - União, Estados e Municípios." (BERCLAZ, 2013, p. 96). Seu surgimento e fundamento jurídico está na Constituição Federal de 1988, que possibilita a participação direta da população na formulação, controle e execução das políticas públicas:

A Constituição de 1988 não só trouxe a cidadania como fundamento da República (artigo $1^{\circ}$, II), como também estabeleceu, no parágrafo único do mesmo dispositivo, o já mencionado princípio da soberania popular "todo o poder emana do povo, que o exerce por meio de representantes eleitos ou diretamente, nos termos desta Constituição". Como já dito, esta mesma Constituição, ao tratar da saúde, assistência social e infância e juventude, deixou clara a necessidade de descentralização do poder e de efetiva "participação da comunidade" (artigo 198, III) e "participação da população, por meio de organizações representativas, na formulação das políticas e no controle das ações em todos os níveis" (artigo 204, II), dispositivo último endossado pelo disposto no artigo $227, \S 7^{\circ}$, da Constituição. Nesses três preceitos constitucionais residem as principais fontes normativas constitucionais que embasam o funcionamento dos conselhos (BERCLAZ, 2013, p. 90) 
Importante ressaltar que, dentre os instrumentos de expressão e participação existentes em nossa Constituição e em outras leis, os Conselhos Gestores recebem destaque, no momento em que institucionalizam o poder de participação da população dentro da estrutura da administração.

Com os conselhos, gera-se uma nova institucionalidade pública. Eles criam uma nova esfera social-pública ou pública não-estatal. Trata-se de um novo padrão de relações entre Estado e sociedade, porque eles viabilizam a participação de segmentos sociais na formulação de políticas sociais e possibilitam à população o acesso aos espaços nos quais se tomam as decisões políticas. Se o Estado e as políticas neoliberais "desconstroem" o sentido do público, retirando sua universalidade e remetendo para o campo do assistencialismo e da lógica do consumidor usuário de serviços, os conselhos têm a possibilidade de reaglutinarem esses direitos fragmentados, reconstituindo os caminhos de construção da cidadania que está sendo esfacelada. (GOHN, 2001, p. 85-88)

A presença deste instrumento participativo na gestão pública municipal representa grande ganho para a cidadania e democratização do Brasil, conquistas de décadas de lutas da sociedade organizada. Para Gohn, a estrutura atual dos Conselhos os insere "na esfera pública e, por força de lei, integram-se com os órgãos públicos vinculados ao poder Executivo, voltados para políticas públicas específicas, responsáveis pela assessoria e suporte ao funcionamento das áreas onde atuam." (GOHN, 2001, p. 84-85)

Entretanto, é importante ressaltar que a Constituição Federal brasileira não dispôs de forma autoaplicável nesta matéria. Não criou, portanto, uma regra geral para a materialização dos conselhos. Caberá às leis infraconstitucionais a regulação e efetivação deste instrumento nas esferas federativas brasileiras, a partir da realidade local. Assim, o que se percebe atualmente é que há uma elevada quantidade de conselhos em todos os níveis da federação, mas muitos deles quais não possuem o efetivo caráter de integração entre a administração e a população. Há uma subutilização deste importante instrumento de participação popular, que ocorre por desinteresse da população em integrá-los e, até mesmo, por desconhecimento, por não compreender qual o seu papel dentro dos conselhos. No entanto, não se pode negar que a "enxurrada" de conselhos, em especial em âmbito local, representa uma nova postura do Estado em relação aos seus administrados, no momento em que os conselhos inauguram uma nova relação permanente e obrigatória entre governo e sociedade na discussão das políticas públicas. (BERCLAZ, 2013, p. 92-96). Nas 
palavras do autor: " Os conselhos representam a institucionalização concreta de uma proposta descentralizada que prevê compartilhamento de poder entre Estado e sociedade civil ". (BERCLAZ, 2013, p. 96).

Os conselhos, poderão ser tanto instrumentos valiosos para a constituição de uma gestão democrática e participativa, caracterizada por novos padrões de interação entre governo e sociedade em torno de políticas setoriais, como poderão ser também estruturas burocráticas formais e/ou simples elos de transmissão de políticas sociais elaboradas por cúpulas, meras estruturas para transferência de parcos recursos para a comunidade, tendo o ônus de administrálos; ou ainda instrumentos de acomodação dos conflitos e de integração dos indivíduos em esquemas definidos previamente. Disso resulta que os conselhos são espaços com caráter duplo: implicam, de um lado, a ampliação do espaço público - atuando como agentes de mediação dos conflitos remando, portanto, contra as tendências das políticas neoliberais de suprimir os espaços de mediação dos conflitos; mas de outro lado, dependendo como são compostos, poderão eliminar os efeitos do empowerment, do sentido de pertencer dos indivíduos, e reafirmar antigas práticas herdeiras do fisiologismo. Como tal, carregam contradições e contrariedades. Tanto podem alavancar o processo de participação sociopolítica de grupos organizados, como estagnar o sentimento de pertencer de outros - se monopolizados por indivíduos que não representem, de fato, as comunidades que os indicaram/elegeram. Eles não substituem os movimentos de pressão organizada de massas, ainda necessários para que as próprias políticas públicas ganhem agilidade. (GOHN, 2001, p. 107-108).

Também é preciso observar o caráter múltiplo do conceito de conselhos gestores que, resumidamente, contém os seguintes elementos: a) refere-se a um grupo de pessoas composto paritariamente por membros representativos de uma parcela da comunidade organizada e membros governamentais; b) que integram uma instituição permanente e reconhecida pelo Estado em todos os níveis da federação com status de exercer uma função pública importante e pró-sociedade, de caráter consultivo e, por vezes, deliberativo na formulação das políticas públicas; c) seus integrantes reúnem-se periodicamente com o intuito de esclarecer dúvidas e discutir de forma democrática temas relacionados à políticas públicas na sua área de atuação; d) objetivam praticar atos voltados ao cumprimento e monitoramento de tais políticas, incluindo a tomada de decisões, para alcançar as finalidades das políticas públicas dentro dos campos administrativo, normativo, de fiscalização etc.; sempre exaltando o desenvolvimento democrático do controle social em conjunto com o Estado. (BERCLAZ, 2013, p. 99-100) 


\section{Revista Brasileira de História \& Ciências Sociais - RBHCS}

Vol. $8 \mathrm{~N}^{\circ}$ 16, Julho - Dezembro de 2016

Assim, Berclaz esclarece que o papel dos conselhos gestores dentro da organização administrativa do Estado é o de ser uma ferramenta institucionalizada de controle social. Para tanto, é necessário delimitar suas múltiplas funções que, dependendo de sua atuação podem se sobrepor uma a outra, ou se caracterizar por dar destaque a uma certa forma de atuação, sendo que um conselho gestor pode desempenhar, conjuntamente ou não, os seguintes papéis: administrativo/burocrático, consultivo, normativo/regulamentar, fiscalizador/controlador e decisório/deliberativo (BERCLAZ, 2013, p. 101).

No tocante ao aspecto administrativo/burocrático, incluem-se todas as atividades de autogestão como: registro das próprias atividades, confecção de atas e pautas das reuniões, organização das reuniões e grupos de estudo etc. No aspecto consultivo, destaca-se a emissão de opiniões e posicionamento por parte dos conselhos a respeito de licenças para atividades e construções, sobre políticas de desenvolvimento urbano, saúde, meio ambiente, educação, etc., no sentido de complementar ou aprimorar o desenvolvimento dos trabalhos do Poder Executivo ou Legislativo com os quais se relaciona. Um exemplo disso é o disposto no artigo 10, § $1^{\circ}$, da Lei 9.790/99, o qual obriga o ente público, antes de estabelecer termo de parceria com entidade privada, consultar o conselho social da área respectiva. Por sua vez, referente ao papel normativo/regulamentar aponta-se a possibilidade dos conselhos editarem resoluções e apresentarem propostas normativas dentro do seu âmbito de atuação. Já o papel fiscalizador/controlador é o que mais caracteriza a atuação dos conselhos gestores, visto como sendo sua função central mais presente nas leis que os regulamentam. Nesse sentido há a previsão de condutas de zelo, avaliação e de acompanhamento das atividades do ente governamental, destacandose pedidos de informação, providência, exame da prestação de contas do Executivo de maneira periódica, bem como pronunciamentos sobre determinada questão no âmbito de sua pasta. Enfim, os aspectos decisórios/deliberativos, juntamente com o fiscalizador/controlador, consistem no reconhecimento pelo ente governamental da relevância dos conselhos gestores como instrumento democrático que, respeitados determinados limites, tem um papel decisivo na edição, formulação, execução e controle das políticas públicas ligadas à sua área de atuação. (BERCLAZ, 2013, p. 102-105)

Em suma, o que se espera de um conselho gestor, quando utilizadas todas as suas possíveis funções e potencialidades, é o desenvolvimento de uma atitude por 


\section{Revista Brasileira de História \& Ciências Sociais - RBHCS}

Vol. $8 \mathrm{~N}^{\circ}$ 16, Julho - Dezembro de 2016

parte da sociedade que questiona, critica, aponta erros, cobra providências e seja capaz de estabelecer diretrizes, juntamente com a sociedade política, em relação a determinados aspectos relacionados às deficiências ou até mesmo inexistência das políticas públicas. (BERCLAZ, 2013, p. 102-105).

Quanto à constituição e organização dos conselhos, Perez (2009, p. 145-147) afirma que a própria lei que cria o conselho pode definir a sua estruturação, composição e forma de atuação, como também é possível elaborar um regimento interno com este objetivo. No entanto, é de responsabilidade da autoridade administrativa possibilitar a estrutura necessária para a constituição e funcionamento dos conselhos, como local adequado, transporte aos seus integrantes para as reuniões, publicação das decisões etc. Já no tocante ao percentual de participação entre representantes da sociedade civil e da Administração Pública, a lei permite livre constituição, destacando que, quanto maior o percentual de composição de representantes da sociedade civil nos conselhos, mais autênticos e ao encontro do princípio constitucional da participação popular se amoldam. E isso se dá sem afrontar o princípio da divisão e da harmonia dos poderes, já que a decisão continua nas mãos do secretário municipal da pasta que é servida pelo conselho gestor, o qual motivadamente, poderá recorrer e anular as deliberações, desde que ilegais ou contrárias aos princípios da Administração Pública.

O conselho gestor integra-se à estrutura orgânica da Administração Pública, muito embora não tenha personalidade jurídica. Por estar integrado à estrutura da Administração Pública, possui acesso a informações, sem restrições, de qualquer órgão público no tocante a subsidiar a tomada da decisão em questão, e esta decisão é, por consequência, ato administrativo ou até mesmo normativo. (PEREZ, 2009, p.142-144)

Muito embora a Constituição Federal de 1988 e as leis regulamentadoras dos conselhos os classifiquem como instituto de caráter deliberativo, consagrando os cidadãos como novos atores deliberativos e paritários com o Estado em parte do processo de gestão, na prática percebe-se um enfraquecimento do instituto, tendo suas decisões um caráter meramente consultivo, o que restringe sua ação a um mero aconselhamento, sem poder de decisão. É preciso fazer cumprir a lei, no sentido de resguardar o caráter deliberativo e vinculativo dos pareceres e decisões emitidas pelos conselhos, em especial no que tange à área ambiental, educacional e de saúde, porque a opinião somente não basta para que a população receba do poder público a 


\section{Revista Brasileira de História \& Ciências Sociais - RBHCS}

Vol. $8 \mathrm{~N}^{\mathrm{O}}$ 16, Julho - Dezembro de 2016

devida atenção e para que as políticas públicas possam contemplar o interesse daqueles que são diretamente afetados por elas. (GOHN, 2001, p. 88-89)

Segundo a autora, há várias lacunas em relação à implantação, papel e funcionamento dos conselhos, além de que, para que estes atuem como órgão deliberativo também é necessária uma transformação da gestão pública, que aceite o conflito de interesses dentro de um país democrático e proporcione esta aproximação da sociedade. Outra dificuldade encontra-se na maturidade da utilização destes instrumentos e no próprio desconhecimento por grande parte da população sobre as possibilidades que os conselhos proporcionam. A falta de tradição participativa e o não interesse da população nas questões políticas do município e até mesmo do país fazem com que o instituto seja ocupado por grupos de interesse ligados ao poder público municipal, utilizado assim como mais um mecanismo legitimador das decisões daqueles que estão próximos ao poder e não como um canal de expressão dos interesses de grande parte da população alijada do processo. Por fim, há ainda o problema da legislação, que não definiu regramentos capazes de garantir uma participação igualitária e equitativa entre a sociedade civil e os representantes da sociedade política e da administração pública (não somente em números, mas, principalmente, em igualdade ao acesso à informação e à capacitação dos conselheiros, para que possam entender a informação e discutir em nível de igualdade com a administração pública). É preciso criar uma estrutura jurídica para que as decisões dos conselhos sejam acatadas pelo gestor público e, ainda, seja garantido que os integrantes do conselho sejam pessoas da sociedade civil que mantenham vínculos permanentes com a comunidade. (GOHN, 2001, p. 90-96)

A realidade atual dos conselhos gestores é a de multiplicação deste instituto em todos os níveis federativos como justificativa da aplicabilidade de práticas democráticas de aproximação da população, muito embora não existam atitudes de suporte político para proporcionar o ideal funcionamento e amadurecimento da ferramenta, sendo muitas vezes usados pelo poder estatal como meros órgãos consultivos e controlados pelo poder Executivo. Em diversos planos pode-se observar da falta de investimentos visando o fortalecimento dos conselhos como, por exemplo: falta de publicidade oficial informando sobre a existência e o papel com conselhos; falta de previsão orçamentária dirigida ao desenvolvimento e funcionamento dos conselhos; inexistência de debate público, transparente e de qualidade com a sociedade sobre a construção e o aprimoramento dos conselhos; enfraquecimento da 


\section{Revista Brasileira de História \& Ciências Sociais - RBHCS}

Vol. $8 \mathrm{~N}^{\circ}$ 16, Julho - Dezembro de 2016

representação da sociedade civil nos conselhos existentes, etc. (BERCLAZ, 2013, p. 97-98)

Tudo o que não se quer é a existência de conselhos gestores que não conseguem cumprir com o seu papel fiscalizador e crítico das políticas públicas oferecidas pelo Estado para o desenvolvimento dos direitos fundamentais dos cidadãos, consequentemente gerando um sentimento de abandono e de descrença pelos participantes, que enxergam no instituto uma possibilidade de exercerem atos de relevante função pública mas que, na prática, estão apenas legitimando decisões unilaterais tomadas pelo Poder Público. (BERCLAZ, 2013, p.106-107)

Do ponto de vista de conteúdo, não pode haver maior fraude e engodo à ideia de democracia deliberativa, do funcionamento dos conselhos sociais, do que a existência simbólica e retórica desses espaços sem nenhum tipo de capacidade de mobilização ou interferência no controle de políticas públicas. (BERCLAZ, 2013, p.106)

A disseminação desse sentimento de descrédito nos institutos de participação no Brasil faz com que se construa uma sociedade civil que, mesmo tendo acompanhado e lutado pela evolução da democracia dentro de um país comandado por elites, ainda não possui a maturidade necessária para as transformações urgentes exigidas pela realidade político-social do país. Há um descompasso entre a realidade legislativa e o real funcionamento das instituições participativas brasileiras. Por isso que o reconhecimento dos conselhos gestores como identidade política e institucional é um processo que demanda tempo e investimento em educação e práticas democráticas, com vistas a corrigir diversos elementos históricos e conhecer outras tantas novas barreiras que precisam ser superadas, visando possibilitar esta possível, mas dificultosa, aproximação e divisão de poder entre a sociedade civil e o Estado. (BERCLAZ, 2013, p.197-198).

Assim, devido à pouca utilização desse instituto pela comunidade que, além de não manifestar vontade de participação política mesmo nos assuntos que lhe interessam, inexiste na sociedade brasileira o sentimento de confiança nos institutos participativos, na maioria das vezes coordenados pelo próprio Estado ou burocratizados de tal forma que impossibilitam a visualização de resolução de problemas com a efetiva participação da sociedade civil. Entretanto, mesmo com tamanhas dificuldades, Gohn destaca que "Os conselhos devem ser espaço e mecanismo operativo a favor da democracia e do exercício da cidadania, em todo e 
qualquer contexto sociopolítico. Eles podem se transformar em aliados potenciais e estratégicos na democratização da gestão das políticas sociais". (2001, p. 105)

Nesse sentido, os conselhos gestores, por estarem inseridos dentro do contexto da aplicação e controle das políticas públicas, não deixam de ser um instrumento que tem por objetivo a defesa e garantia no mundo real dos direitos fundamentais previstos na Constituição Federal Brasileira, conforme defende Eduardo Cambi:

\begin{abstract}
A efetividade não se apresenta como condição ulterior do direito, mas antes, como condição de existência do próprio direito. Não basta, pois, o reconhecimento formal dos direitos fundamentais, imprescindível meios para concretizá-los. Os direitos fundamentais (sociais) são realizados a partir de um conjunto de atividades denominado de políticas públicas - que devem ser realizados pela Administração Pública, para que os fins previstos na Constituição sejam cumpridos. Em sentido amplo, o termo políticas públicas abrange a coordenação dos meios à disposição do Estado para a harmonização das atividades estatais e privadas, nas quais se incluem a prestação de serviços e a atuação normativa, reguladora e de fomento, para a realização de objetivos politicamente determinados e socialmente relevantes. Enfim políticas públicas são metas políticas conscientes ou programas de ação governamental, voltados à coordenação dos meios à disposição do Estado e das atividades privadas, com a finalidade de realizar objetivos socialmente relevantes e politicamente determinados (CAMBI, 2011, p. 190)
\end{abstract}

Segundo Gohn (2001, p.110), os conselhos gestores não influenciam somente a gestão das políticas públicas, mas fazem parte de um novo modelo de desenvolvimento Estatal:

[...] gestão publica estatal via parcerias com a sociedade civil organizada objetivando a formulação e o controle de políticas sociais. Em uma sociedade marcada por inúmeros processos de exclusão social e de baixos níveis de participação política do conjunto da população, os conselhos assinalam para possibilidades concretas de desenvolvimento de um espaço público, que não se resume e não se confunde com o espaço governamental/estatal. (GOHN, 2001, p. 110)

No momento em que os conselhos gestores somente existem no ordenamento brasileiro devido às conquistas dos movimentos sociais organizados, consagrando-se em instrumentos de representação da sociedade, e, por lei, também espaços de decisão, faz-se necessário desenvolver dentro da gestão pública e na sociedade civil condições para que eles tenham real eficácia na área de atuação e para a sociedade, tais como: a) dar peso político a essa modalidade de representatividade; b) aumento efetivo de recursos públicos nos orçamentos destinados aos conselhos; c) paridade 


\section{Revista Brasileira de História \& Ciências Sociais - RBHCS}

Vol. $8 \mathrm{~N}^{\circ}$ 16, Julho - Dezembro de 2016

nas condições de acesso e de participação da sociedade civil na composição dos conselhos; d) que em médio prazo evolua e transforme-se em um canal de mediação de conflitos sociais e não somente de tratamento de questões pontuais e imediatistas filtradas pelo poder público; e) possibilitar cursos de atualização para os conselheiros, estes assumindo o papel de porta voz da sociedade que representam, mantendo um vínculo contínuo com ela; f) estipular pré-requisitos, fiscalização e possibilidade de perda do mandato dos conselheiros que não atuem em prol da coletividade; g) transformar o conselho gestor municipal em instância deliberativa e não meramente consultiva. (GOHN, 2011, p. 110-112)

Para que o Estado brasileiro evolua para uma sociedade efetivamente participativa, com os direitos de cidadania respeitados e exercidos em várias dimensões, é necessária vontade política dos representantes do povo. Ou seja, “a exigência de uma democracia participativa deve combinar lutas sociais com lutas institucionais, e a área da educação é um grande espaço para essas ações, via a participação nos conselhos" (GOHN, 2001, p.106)

Para que a essência das funções dos conselhos sociais não seja perdida, esses preciosos e diferenciados atores não podem ser meros agentes instrumentais legitimadores de escolhas pré-concebidas e não discutidas de modo a respeitar a autonomia da sociedade e, portanto, subservientes ao interesse do governo, mas sim espaços de controle social e inversão de prioridades para que as políticas sejam de estados e permanentes e não meramente passageiras e mutáveis ao sabor da agremiação partidária que está no poder. (BERCLAZ, 2013, p.108)

Por mais que sejam alvos de críticas sobre a capacidade de desenvolvimento de uma nova política via conselhos gestores, é inegável reconhecer que eles permitem a coexistência e complementaridade entre diversos modelos de democracia. Podem transformar-se em espaços produtores de um novo modo de se formular as políticas públicas e dar uma "nova cara” às alternativas propostas pelo poder público, que terá subsídios diretamente das pessoas afetadas pelas políticas públicas. O que se busca nos conselhos gestores é o desenvolvimento de um espaço livre e crítico, capaz de reconhecer os limites do poder público sem deixar de transformar a realidade brasileira mediante a crítica, a análise e o estudo. Cria-se uma postura nova e transformadora por parte da sociedade civil, que deve buscar respostas e não apenas aguardar por desculpas quando se trata de violação aos seus direitos fundamentais mais básicos. Sair do conformismo e da apatia política, permitindo que os 


\section{Revista Brasileira de História \& Ciências Sociais - RBHCS}

Vol. $8 \mathrm{~N}^{\mathrm{o}}$ 16, Julho - Dezembro de 2016

verdadeiros donos do poder, a sociedade civil, tenham voz ativa e que o Estado e os governantes assumam um papel mais responsável e menos autoritário em razão da população. É preciso "reconhecer os conselhos sociais como espaços de hiperpotentia (é a vontade de poder (soberania) do povo) é fazer prevalecer a vontade-de-viver da comunidade em detrimento da vontade-de-poder do governante, viabilizando a tomada de consciência crítica (incluindo a percepção de "ser" povo)”. (BERCLAZ, 2013, p. 216)

Ao se construir uma compreensão abrangente sobre as diversas funcionalidades praticadas dentro dos conselhos gestores, reforça-se o seu papel de intermediário entre população e Estado, aproximando o povo e poder político, caracterizando o instituto como um local de constituição de sujeitos democráticos capazes de atuar na cogestão das políticas públicas. Para Berclaz, é preciso entenderse “os conselhos sociais como sujeitos sócio-históricos emergentes dentro da sociedade civil brasileira capazes de constituir uma verdadeira e cotidiana frente de libertação a partir da prática de sua atuação” (BERCLAZ, 2013, p. 206)

Com o desenvolvimento dos conselhos gestores torna-se possível que dois importantes postulados da democracia contemporânea, a democracia direta e a busca de identidade entre representante e representado, tornem-se mais próximos e alcançáveis, como conseqüência da ampliação da participação política proporcionada pelo instituto. Mesmo sendo instâncias formais e institucionais, "situam-se dentro da atmosfera de uma esfera pública ampliada capaz de propiciar uma governança local que estimula e amplia a possibilidade de participação política do povo na sinalização das suas prioridades, carências e necessidades, otimizando as chances do governo reagir adequadamente frente a esses problemas”. (BERCLAZ, 2013, p. 221)

Por sua vez, no tocante ao aspecto educativo, o desenvolvimento de espaços abertos para a participação da população nos moldes dos conselhos gestores é capaz de promover uma verdadeira revolução cultural dentro de uma sociedade.

Para além dos benefícios constatáveis na realidade política objetiva, como outra decorrência positiva da identidade política dos conselhos, há de se reconhecer o fato de essas instâncias de participação ampliada exercerem o papel de genuínas agências culturais responsáveis pela socialização política e promoção educativopedagógica para fortalecimento da cidadania e da democracia, seja diretamente para os membros não governamentais (e movimentos sociais) que o integram, seja indiretamente para a sociedade neles representada que pode acompanhar e se beneficiar com o bom desempenho de suas atividades. (BERCLAZ, 2013, p. 219) 
Além de desenvolver a cultura democrática, colaborando de forma pedagógica para o desenvolvimento da cidadania e para aumento do interesse pelas questões político-sociais, mediante conselhos efetivamente populares e deliberativos possibilita-se gerar um sentimento de confiança na população na ordem política, na democracia e uma melhor compreensão da verdadeira função do Estado e do próprio cidadão.

Os conselhos são novas gramáticas sociais determinantes de que a
democracia da ordem política vigente não se resuma ao modelo
normativo representativo, mas, ao contrário, incorpore e absorva
novas e combinadas formas participativas, deliberativas, quando não
propriamente radicais. Ao permitirem o tempero de uma democracia
eminentemente representativa por momentos de democracia direta
nas modalidades participativa/participativa/radical, os conselhos
sociais cumprem com o princípio formal essencial de legitimidade
justificador de sua criação, permitindo que seja revigorada crenças na
democracia, na política e, consequentemente, na própria função do
Estado, medida absolutamente necessária em contexto em que a
corrupção, especialmente pela forma como é divulgada pela grande
mídia (com sensacionalismo efêmero e sem conteúdo crítico-
informativo com poder mobilizatório), não raras vezes dissemina
conformismo e alienação. (BERCLAZ, 2013, p. 219-220)

Não se pode negar que os conselhos gestores representam uma inovação na gestão das políticas públicas no Brasil. Impossível seria afirmar o seu futuro sem que o país passe por um tempo de experimento e amadurecimento do instituto. Somente a sua existência não é suficiente para concluir se, de fato, os conselhos serão instrumentos de transformação democrática, capazes de criar uma nova relação entre sociedade civil e Estado, mudando a tendência clientelista e assistencialista da política atual, que cerceia a democracia e restringe inovações.

Há vários caminhos para os conselhos gestores neste século XXI. Um deles é evoluir para uma administração que aceita conflitos e cria espaços de mediação desses conflitos em conformidade com o significado da democracia, nos quais os conselhos gestores podem se consagrar como espaços de formulação de políticas públicas elaboradas a partir das necessidades da sociedade, que são representadas nas deliberações tomadas democraticamente nos conselhos gestores. $\mathrm{O}$ outro caminho é utilizar-se dos conselhos como meio para o Estado acomodar conflitos, cujas discussões já apresentam respostas pré-definidas para os problemas debatidos, o que nada acresce para o desenvolvimento da democracia; pelo contrário, utiliza-se 


\section{Revista Brasileira de História \& Ciências Sociais - RBHCS}

Vol. $8 \mathrm{~N}^{\circ}$ 16, Julho - Dezembro de 2016

de mais um instituto dentro da burocracia do aparato estatal, meramente consultivo, com intuito de legitimar e ratificar a opinião preconcebida dos governantes e atender a uma exigência legal para que os recursos cheguem ao município e tenham o destino que a camada social com mais influência política achar que devam ter. (GOHN, 2001, p. 107-110)

Assim como em toda evolução da humanidade, somente o tempo trará as respostas. Muito embora a institucionalização dos conselhos gestores represente um avanço democrático para o país, somente a constituição do instituto e sua disponibilidade à população não são suficientes para a construção de uma sociedade democrática. É preciso que a cidadania se organize e desenvolva atitudes pró-ativas em prol do desenvolvimento local. Sem que as instituições privadas, públicas e as organizações da sociedade civil andem de mãos dadas, resgatando um espírito de cooperativismo, de solidariedade e de parceria, impossível será o fortalecimento da democracia no Brasil e o desenvolvimento de uma cultura participativa dentro de cada cidadão e do próprio Estado.

O grande desafio dos governos locais e das instituições que buscam a participação ativa da sociedade nas questões públicas não está isolado da tarefa de coordenação e de regulação do processo em nível local. Está na capacidade de paulatinamente gerar alianças e ações conjuntas com outros atores, estatais ou não, na busca de construir um ambiente onde a gestão local seja compartilhada. E, nesse sentido, incremento do papel dos conselhos gestores municipais na formulação cogestionada das políticas públicas é um importante caminho a ser incrementado.

\section{CONSIDERAÇÕES FINAIS}

Ao analisar um dos principais instrumentos existentes no Brasil na esfera do Poder Executivo que buscam, mediante o Princípio da Participação, garantir o cumprimento dos direitos fundamentais previstos na Constituição Federal de 1988 por parte do Estado em conjunto com a comunidade, conclui-se que os conselhos gestores municipais justificam a existência do Estado como verdadeiro guardião do regime democrático brasileiro

A democracia deve significar muito mais do que votar e ser votado. Em um

regime democrático participativo é preciso que cada cidadão, individual e coletivamente considerado, exerça um papel ativo na política brasileira, controlando 


\section{Revista Brasileira de História \& Ciências Sociais - RBHCS}

Vol. $8 \mathrm{~N}^{\mathrm{o}}$ 16, Julho - Dezembro de 2016

a atuação de seus representantes e, por vezes, participando conjuntamente da definição as tutelas jurídicas e políticas em âmbito municipal.

Nota-se dois importantes aspectos no instituto estudado: a existência, mesmo que tímida, dos conselhos gestores municipais, representa um grande avanço democrático para o país, porém, as dificuldades de sua concreta efetivação como elo de ligação entre sociedade civil e sociedade política ainda é algo importante a ser superado. A falta de interesse político do cidadão, que vive um momento de apatia política em meio a atitudes corruptas e antidemocráticas de seus representantes, conjugada a um aparato estatal pautado na democracia representativa, acostumado a deter o poder entregue pela população e não sofrer por parte desta nenhum tipo de cobrança ou fiscalização, são situações nocivas e prejudicam a participação popular como um todo.

Nota-se que o Brasil carece de políticas educacionais voltadas ao desenvolvimento de uma consciência política e de práticas democráticas no cotidiano das instituições brasileiras. Muito embora existam dificuldades, a implementação paulatina de novos institutos que visem desenvolver uma participação ativa da sociedade em conjunto com o governo local, é o único caminho para proporcionar a superação deste estado de apatia generalizada. É preciso fomentar espaços para cobrar junto ao Estado realizações palpáveis, acompanhar e fiscalizar a atuação dos representantes políticos em busca ao atendimento das garantias fundamentais presentes na Constituição Federal, que nada mais são que condições mínimas para obtenção de uma vida digna.

A verdade é que a comunidade clama pelo real oferecimento de espaços abertos de participação, onde possa expor suas idéias, reivindicando uma política mais voltada aos seus interesses prioritários. Não quer ser mera expectadora de decisões centralizadas do órgão municipal, o qual executa planos antes, e só depois procura saber - quando procura - sobre a satisfação do povo. O gestores públicos municipais acreditam conhecer todo seu espaço de atuação, e que não é necessário a participação dos cidadãos para estabelecer quais as ações de maior urgência. Mas essa realidade deve ser modificada, não somente por ser um clamo social, mas também por ser imposição legal.

Enfim, o processo de gestão democrática na cidade somente será possível por meio da articulação entre Poder Público e cidadãos, através de mecanismos que devem ser implantados gradativamente e de forma organizada. É preciso possibilitar 
que a tomada de decisões seja feita por todos, com iguais oportunidades, o que ocasionará a racionalização de recursos e a redescoberta da cidadania em cada um, levando a um maior comprometimento com o social. Só assim ter-se-á uma gestão democrática participativa, de todos e para todos, construindo uma cidade mais humana e mais digna de se viver.

Toda evolução social, política, econômica e cultural carece de tempo para se realizar. Assim como em toda a história da humanidade, também no Brasil, para que haja uma transformação cultural na sociedade demanda-se de tempo, de tentativas, avanços e recuos, de mudanças e vários refazeres para que se alcance a transformação política almejada, para que se subverta interesses clientelísticos e privatísticos que preponderaram na história política brasileira e possa ser aberto um caminho profícuo na busca de objetivos prioritários da sociedade civil, na prática ainda muito distante do exercício do poder político no país.

\section{REFERENCIAS}

BERCLAZ, Márcio S. A natureza político-jurídica dos conselhos sociais no Brasil: uma leitura a partir da política da libertação e do pluralismo jurídico. Dissertação (Mestrado), Universidade Federal do Paraná, Curitiba, PR, 2013.

CAMBI, Eduardo. Neoconstitucionalismo e neoprocessualismo: direitos fundamentais, políticas públicas e protagonismo judiciário. 2a edição, São Paulo: Revista dos Tribunais, 1986.

CARVALHO, Ana Maria de. O Orçamento Participativo como instrumento de gestão que oferece a efetivação da cidadania em sua plenitude. Disponível em

http://gestaocompartilhada.pbh.gov.br/sites/gestaocompartilhada.pbh.gov.br/files/ biblioteca/arquivos/op como instrumento de gestao e cidadania o.pdf, consultado em 10/1/2016.

DEMO, Pedro. Participação é Conquista: Noções de Política Social Participativa. 2a edição, São Paulo, Cortez, 1993.

GOHN, Maria da Glória. Conselhos gestores e participação sociopolítica. Questões da nossa época. v. 84, São Paulo: Cortez, 2001.

GOHN, Maria da Glória. Educação não formal e cultura política: impactos sobre o associativismo do terceiro setor. Questões da nossa época. v. 26, São Paulo, Cortez, 2011.

GRAZIA, Grazia de. Estatuto da Cidade: Uma Longa História com Vitórias e Derrotas. In: OSÓRIO, Letícia Marques (Org). Estatuto da Cidade e Reforma Urbana: Novas Perspectivas para as Cidades Brasileiras, Porto Alegre: Sergio A. Fabris, 2002. 
LUCAS, John Randolph. Democracia e Participação. Tradução de Cairo Paranhos Rocha. Brasília: Universidade de Brasília, 1985.

MOREIRA NETO, Diogo de Figueiredo. Mutações do Direito Administrativo. 2a edição, Rio de Janeiro: Renovar, 2001.

. Direito da Participação Política: Legislativa, Administrativa, Judicial: (Fundamentos e Técnicas Constitucionais da Legitimidade). Rio de Janeiro: Renovar, 1992.

PATEMAN, Carole. Participação e Teoria Democrática. Tradução de Luiz Paulo Rouanet. Rio de Janeiro: Paz e Terra, 1992.

PEREZ, Marcos A. A Administração Pública Democrática: Institutos de Participação Popular na Administração Pública. Belo Horizonte: Fórum, 2009.

SANTIN, Janaína Rigo; FINAMORE, Eduardo B. A gestão democrática municipal e o papel dos conselhos em Passo Fundo. Revista História: debates e tendências, v. 7, n. 2, pp. 204-225, 2007.

TEIXEIRA, Elenaldo Celso. O Local e o Global: limites e desafios da participação cidadã. 3a edição, São Paulo: Cortez, 2002.

Recebido em Março de 2016 Aprovado em Novembro de 2016 